\title{
FORMAÇÃO DE RECURSOS HUMANOS PARA ATUAR EM SUPERVISÃO DE MÓDULO BÁSICO DE SAÚDE PÚBLICA
}

\author{
Luzia da Silva* \\ Maria Auxiliadora Córdova Christófaro ** \\ Maria Girlene Martins*** \\ Maria Rizoneide Negreiros de Araújo**** \\ Roseni Rosângela Chompré*
}

SILVA, L. da; CHRISTOFARO, M. A. C.; MARTINS, M. G.; ARAÚJO, M. R. N. de; CHOMPRÉ, R. R. Formação de recursos humanos para atuar em supervisão de módulo básico de saúde pública. Rev. Esc. Enf. USP, São Paulo, 19(1): 75-80, 1985.

As autoras relatam uma experiência de colaborafão entre a Escola de Enfermagem da Universidade Federal de Minas Gerais - por intermédio de docentes do Departamento de Enfermagem Materno-Infantil e de Saude Pública e de alunos matriculados no Curso de Habilitação em Enfermagem de Saúde Pública - e quatro Centros Regionais de Saúde da Secretaria de Estado da Saúde de Minas Gerais. $O$ objetivo foi experimentar um modelo de supervisão do pessoal de enfermagem e de "educação continua" do mesmo. A conclusão mais importante emergente da experiência foi a necessidade de trabalharem em conjunto os órgãos de formaçđo de recursos humanos e os de prestação de serviço. Foi proposta a criaçao de mecanismos para que a experiência se tornasse em metodologia de assistência e ensino.

\section{INTRODUÇÃO}

Durante o ano de 1982, a Escola de Enfermagem da UFMG, através do Departamento de Enfermagem Materno-Infantil e. Saúde Pública (DEMISP), desenvolveu o Curso de Habilitação em Enfermagem de Saúde Pública integrado aos Serviços Básicos de Saúde da Secretaria de Estado da Saúde (SES-MG).

- Professor Assistente do Departamento de Enfermagem Materno-Infantil e Saúde Pública da Escola de Enfermagem da UFMG.

** Pró-Reitora de Graduação da UFMG.

*** Professor Assistente do Departamento de Enfermagem Aplicada da Escola de Enfermagem da UFMG.

**** Diretora da Escola de Enfermagem da UFMG. 
A proposta foi apresentada pela Organização Panamericana de Saúde (OPS), Ministério da Saúde (MS) e- Secretaria de Estado da Saúde de Minas Gerais (SES-MG) e aceita pela Escola de Enfermagem em outubro/81, após um Encontro Inter-regional realizado em Montes Claros. Dele participaram parte dos alunos matriculados no referido curso. A atividade teve o caráter de experimento.

Pela SES-MG, integraram a experiência quatro Centros Regionais de Saúde (CRS): Barbacena, Montes Claros, Divinópolis e Patos de Minas, além de setores da Coordenação Central.

Do processo desencadeado nas Instituiçð̃es de Serviço e de Formação, com a incorporação da proposta, enquanto experimento pedagógico e de prestação de serviço, é fundamental assinalar alguns pontos discutidos não só na fase de apresentação e conhecimento do proposto, como também durante a sua execução e sua avaliação. São eles:

- qual o objetivo da Instituição Prestadora de Serviço, quando propõe realizar seu serviço, através da participação de estudantes e professores integrados à suas equipes de execução e supervisão; e

- como, a partir da prestação de serviço, as Escolas poderão realizar seus objetivos essenciais, sem incorrer em equívocos de condução que as afastem do processo ensino/aprendizagem.

É importante ressaltar que este experimento originou-se de necessidade dos órgãos de saúde, OPS, MS e SES-MG, e foi proposto à Escola no momento que, mais uma vez, o Departamento de Enfermagem Materno-Infantil e de Saúde Pública enfrentava a necessidade de se instrumentalizar para proceder à avaliação do seu curso, especificamente de Habilitação em Enfermagem de Saúde Pública.

\section{O PROJETO EXPERIMENTAL DE SUPERVISÃO DE MÓDULOS BÁSICOS}

\section{Pressupostos}

Ao nível dos órgãos de saúde, são pressupostos que podem ser explicitados, a partir da análise da proposta inicial apresentada à Escola de Enfermagem em Montes Claros:

- a supervisão, como função inerente ao processo de trabalho, que, enquanto ofício, divide-se em tarefas, está ligada indissoluvelmente ao CONTROLE e à FISCALIZAÇÃO, e que, através de prêmio, punição ou persuasão, faz coincidir os objetivos do nível regional com os da instituição a nível central;

- a necessidade de rever o processo de supervisão implantado é uma preo- 
cupação dos que se acham empenhados no desenvolvimento de Programas de Extensão de Cobertura de Serviços de Saúde, porém, esta necessidade tem-se limitado ao nivel central, às generalidades, não contribuindo para orientações práticas;

- ultrapassar esse nível (central e de generalidades) só será possível se o questionamento da supervisão ocorrer a partir do módulo básico, estendendo-se para a equipe regional, reforçando ou redefinindo propostas tais como equipe multiprofissional, supervisor polivalente, que inexoravelmente surgirão no processo experimental proposto; a estratégia para desencadear este processo será a inserção de um profissional de "formação técnico-específica" entre a equipe regional e o módulo básico para, prioritariamente, controlar a variável "treinamento em serviço do pessoal auxiliar", uma vez que este ponto aparece, de forma consensual, como um dos estrangulamentos da supervisão. (Proposta Inicial do Projeto Experimental em Módulo Básico apresentado em Montes Claros - outubro/81).

\section{OBJETIVO GERAL}

"Experimentar, em áreas reduzidas (módulos básicos ou áreas programáticas), um modelo de supervisão em serviços básicos de saúde, buscando especialmente soluçð̃es para problemas relacionados com a educação continuada do auxiliar de saúde".

Quando discutido, do ponto de vista dos objetivos da formação específica do enfermeiro na área de Saúde Pública, constatou-se uma defasagem. $O$ objetivo inicial não contemplava todas as necessidades da Escola, que estabelece, como objetivo final do curso de Habilitação em Enfermagem de Saúde Pública, "a inserção dos seus alunos nos órgãos de serviço de saúde coletiva, na realização de funçōes administrativas, assistenciais e de ensino".

Apesar da defasagem referida, a Escola absorveu este projeto, considerando-o capaz de gerar uma nova dinâmica do ensino, imprescindível para a formação, como também para a avaliação da sua prática.

Definindo-se pela participação neste Projeto, o Departamento de Enfermagem Materno-Infantil e de Saúde Pública considerou que:

1. estando o aluno na base dos serviços de prestação de assistência à saúde;

2. sendo-lhe assegurada a possibilidade real de participar da discussão da equipe de supervisão regional, de elaborar, propor, implementar, executar e avaliar a assistência de saúde a nível local;

3. sendo-lhe também assegurada a oportunidade de supervisionar e treinar pessoal auxiliar, como inicialmente foi colocado pelos órgãos de saúde, garantia-se sua capacitação técnica e a ampliação do seu campo de reconhecimento e de crítica em relação ao papel e função do enfermeiro den- 
tro da política de saúde. Daí poderiam surgir, também, os referenciais de avaliação da Escola enquanto órgão formador.

\section{Principio}

O princípio norteador do projeto, traçado a partir da discussão da proposta inicial entre a Escola e os órgãos de serviço, foi integrar os órgãos de formação com os de Serviço, através de um experimento no nível de supervisão. Esta integração garantiria:

1. a fixação do aluno no módulo básico, permitindo sua participação na produção de serviços de saúde;

2. a aplicação, em situação real e concreta, do conteúdo acadêmico ministrado no Curso de Habilitação em Enfermagem de Saúde Pública.

Seria, assim, possível para o aluno, questionar e testar o conteúdo acadêmico e resgatar, para a Escola e para o Serviço, através de discussão, críticas e propostas alternativas, seu papel social e técnico, assim como subsidiar suas avaliações e propostas pedagógicas e de assistência.

\section{O PROJETO EXPERIMENTAL DE SUPERVISÃO EM MÓDULOS BÁSICOS}

\section{Execução e avaliação}

De março a dezembro de 1982 (10 meses), oito alunos e cinco professores da Escola de Enfermagem integraram-se no Projeto Experimental de Supervisão nos Módulos Básicos.

O projeto foi desenvolvido nos quatro Centros Regionais de Saúde (CRS) acima citados, como proposto pela SES-MG: CRS de Barbacena, CRS de Divinópolis, CRS de Montes Claros e CRS de Patos de Minas. gulos:

A execução e avaliação do "Projeto" podem ser apresentadas sob três ân-

Do ponto de vista do serviço prestado nos módulos básicos

Foi considerada expressiva a atuação do estagiário, tanto no atendimento à demanda dos Centros e Postos de Saúde, como no treinamento e na reciclagem do pessoal auxiliar. A implementação de propostas e atividades de saúde junto aos Centros de Saúde e grupos comunitários significou uma ampliação do papel destes serviços.

O treinamento desenvolvido demonstrou não só a capacidade do estagiário para realizá-lo, como também a importância do treinamento de pessoal auxiliar. Este ocorreu de forma sistemática, respondendo às necessidades locais de serem acompanhados contínua e regularmente. Tais características 
são impossíveis de serem complementadas pela Equipe de Supervisão Regional.

\section{Do ponto de vista da Supervisão}

A redefinição ou reforço da experiência de supervisão implantada no Estado de Minas Gerais só ocorrerá quando as equipes regionais estiverem presentes no processo de discussão e realmente sentindo a necessidade de se discutir a estrutura político-técnico-administrativa.

Neste sentido, registra-se que, de acordo coma fase de cada Centro Regional de Saúde e as bases sobre as quais as discussões ocorreram, os critérios de avaliação do projeto variaram, se não na sua natureza pelo menos no grau, uma vez que seria, no mínimo, artificial usar critérios idênticos para avaliar realidades desiguais. Recomendou-se que não fossem perdidas, no bojo da avaliação, as características de cada Centro Regional de Saúde, trabalho que de alguma forma delineia o perfil de cada regional, bem como os "porquês" que cada equipe considerou ao conceber, coordenar e executar a supervisão. A tentativa de apresentar a supervisão como uma prática linear, executada de forma homogênea em todos os CRS, foi considerada como situação ideal, porém, a realização do projeto na forma original não coincidia com a realidade encontrada. Se a situação real verificada posteriormente não coincidiu com o "ideal" apresentado, questðes de grande relevância, surgidas no transcurso do projeto, devem ser avaliadas e analisadas. Algumas sobressaem:

- A equipe multiprofissional funciona como polivalente ou se limita a identificar os problemas e encaminhá-los a determinado especialista da equipe?

- A execução de programas verticais atende realmente a demanda da população ou é apenas a execução de tarefas prescritas a nível central para facilitar o controle?

- As atividades de saúde implantadas nos serviços básicos é uma resposta médica indivualizada aos sinais e sintomas de doença da população carente?

\section{Do ponto de vista da formação do Enfermeiro de Saúde Pública}

Neste ponto, cabe ressaltar as discussões internas da Escola em relação aos princípios filosóficos, políticos e pedagógicos do seu próprio currículo, que atualmente está quase totalmente voltado para atenção de saúde no campo hospitalar. Recai sobre o curso de Habilitação (uma concentração na área de Saúde Pública subseqüente à graduação do enfermeiro) a tarefa de resgatar não só o conteúdo básico para o atendimento de saúde voltada para a atenção primária, como também o conteúdo técnico-científico de Saúde Pública; assim sendo, a avaliação crítica deste Projeto poderá gerar para a Escola de Enfermagem uma discussão mais profunda sobre a necessidade de incor- 
poração do saber específico sobre Saúde Pública na formação do enfermeiro geral, como princípio e prioridade.

Isto posto, há de se fazer referência às questões administrativas e aos encargos funcionais, tanto dos professores como dos supervisores. A partir do momento que o Projeto foi iniciado, não foi possível qualquer redistribuição das atividades específicas dos docentes. Conjugaram-se as seguintes atividades às já existentes: implantar o Projeto, supervisioná-lo, orientar os alunos e participar de reunióes gerais de avaliação e acompanhamento nos diversos tipos do serviço.

\section{CONCLUSÃO}

Cada vez mais confirma-se para a instituição formadora a importância do trabalho integrado com os órgãos de Serviços de Saúde. Esta integração subsidia não só a avaliação da adequação técnico-científica do profissional, como, também, cria instrumento de mudança, intervenção e crítica do papel desempenhado pelas Universidades na formação de profissionais da área de Saúde e pelos Órgãos de Serviços na prestação de assistência de saúde.

Foi proposta a criação de mecanismos, entre as duas instituiçð̃es para que a experiência seja transformada em metodologia de assistência e ensino, e de infraestrutura, que atenda às necessidades geradas por este modelo de ensino.

SILVA, L. da; CHRISTOFARO, M. A. C.; MARTINS, M. G.; ARAUUJ, M. R. N. de; CHOMPRE, R. S. Preparation of nurses for supervision in health centers. Rev. Esc. Enf. USP, São Paulo, 19(1): 75-80, 1985.

The authors describe an experiment on cooperation between a school of nursing through instructors and some students enrollded in the Public Health Nursing Program - and from Regional Health Centers. The objective was to experiment the application of a "model" of supervision of nursing personnel and of continued education. The most important conclusion was the need of close cooperation between educational and service instituitions for efficient preparation of the working personnel. 